\title{
LOS ORÍGENES Y LA DURABILIDAD DE LA DEMOCRACIA eN AMÉrica LATINA: AVANCES y Retos \\ DE UNA AGENDA DE INVESTIGACIÓN
}

\section{The Origins and Durability of Democracy in Latin America: Advances and Challenges of a Research Agenda}

\section{GERARDO L. MUNCK*}

Colegio de Relaciones Internacionales, Universidad del Sur de California

\begin{abstract}
RESUMEN
Este artículo ofrece una visión general de la literatura sobre la lucha por la democracia en América Latina. Después de introducir la agenda de investigación sobre regímenes políticos y democracia en América Latina, se enfoca en los debates teóricos acerca del origen y la durabilidad de la democracia, y discute las principales ideas y críticas teóricas así como los hallazgos de la investigación empírica. La discusión está organizada en torno a cinco líneas de investigación, sobre la modernización económica, la cultura, el desarrollo capitalista y las clases sociales, las coyunturas críticas, y lo político-institucional. Las fronteras de la investigación sobre democracia en América Latina son también abordadas.
\end{abstract}

Palabras clave: Democracia, regímenes políticos, América Latina.

\begin{abstract}
This article offers an overview of the scholarship on the struggle over democracy in Latin America. After introducing the research agenda on political regimes and democracy in Latin America, it focuses on the main explanatory theories and debates about the origins and durability of democracy, and discusses theoretical ideas and critiques as well as the findings of empirical research. The discussion is organized around five lines of research, on economic modernization, culture, capitalist development and class, critical junctures, and the political-institutional. The frontiers of research on democracy in Latin America are also addressed.
\end{abstract}

Key words: Democracy, political regimes, Latin America.

* Agradezco a Mariano Bertucci, Sebastián Mazzuca, Richard Snyder y dos revisores anónimos por sus muy útiles sugerencias. La traducción al castellano fue hecha por Claudia Luera. 
La opción entre democracia y sus alternativas ha sido un eje central de los conflictos políticos en Latinoamérica desde los comienzos del siglo XX. Un preludio indispensable de estos conflictos fue el proceso de formación del Estado, que ocupó el centro de la escena de la vida política luego de la consecución de la independencia de los países latinoamericanos hace aproximadamente 200 años. Pero, en la medida que el proceso de formación del Estado generó un centro de poder político reconocido y por lo tanto una semblanza del orden político, la lucha entre fuerzas a favor y en contra de someter el poder político al control democrático ganó centralidad.

La historia de la lucha por la democracia en América Latina es relativamente extensa y variada. Las muestras más palpables de esta lucha fueron las olas de democratización y desdemocratización, esto es, las fluctuaciones hacia y desde la democracia, que barrieron la región luego de la Segunda Guerra Mundial, y que involucraron un período largo de autoritarismo duro en las décadas de 1960 y 1970 y las transiciones hacia la democracia en las décadas de 1980 y 1990. A partir de entonces, se abrió una nueva y extremadamente positiva fase en la vida política de la región. Los temores de una vuelta al autoritarismo resultaron ser injustificados y gradualmente la democracia asumió el estatus de norma regional. En efecto, un hecho inequívoco en la política latinoamericana en el siglo XXI es que nunca antes tantos países de la región habían sido democráticos por tan largo tiempo.

Sería un error, no obstante, asumir que la lucha por la democracia puede ser tomada como un asunto concluido. Los análisis de la política en América Latina en el siglo XXI pueden legítimamente abordar el funcionamiento de la democracia, como ha sido habitual en el estudio de las democracias establecidas en los países ricos. Pero la política contemporánea en América Latina no puede ser reducida a conflictos que se encauzan en su totalidad dentro de las reglas institucionales de la democracia, como si los conflictos en torno a esas reglas hubieran dejado de ser relevantes. Más bien, como insisten observadores agudos de la actualidad política de América Latina, la lucha por la democracia continúa latente bajo la superficie y ocasionalmente estalla en conflictos políticos abiertos. En otras palabras, la historia de la democracia continúa desarrollándose.

Con el fin de evaluar qué hemos aprendido acerca de la democracia en América Latina y de orientar las investigaciones futuras, este artículo ofrece una visión general de los estudios que se han ocupado de la lucha por la democracia en América Latina. La primera sección sitúa el estudio de la política en América Latina dentro del campo más amplio de la política comparada, traza los orígenes de una agenda de investigación enfocada en los regímenes políticos y la democracia en América Latina, y resalta las características clave de esta agenda.

La segunda y más extensa sección se enfoca en los debates teóricos sobre el origen y la durabilidad de la democracia, entendida como un tipo de régimen político. La discusión está organizada en torno a cinco líneas de investigación, sobre la modernización económica, la cultura, el desarrollo capitalista y las clases sociales, las coyunturas críticas, y lo político-institucional. Bajo estos cinco encabezamientos, se discuten las principales ideas y críticas teóricas, y se resumen los hallazgos de la investigación empírica. 
Por último, la tercera sección considera las fronteras de la investigación actual sobre la democracia en América Latina. Se resaltan algunos retos relacionados con preguntas viejas ligadas a una definición minimalista de la democracia. Además, se especifican preguntas nuevas que conciernen a otros aspectos de la democracia. En breve, este artículo se centra en la agenda de investigación sobre regímenes políticos y democracia en América Latina y, por medio de una evaluación comprensiva de la literatura, identifica los avances y retos más significativos de esta agenda de investigación.

\section{REGÍMENES Y DEMOCRACIA EN AMÉRICA LATINA: UNA AGENDA DE INVESTIGACIÓN}

La política en los países de América Latina fue raramente estudiada en la política comparada, el campo académico dentro de la ciencia política dedicado al estudio de la política alrededor del mundo, durante el período fundacional de este campo en la primera parte del siglo XX. ${ }^{1}$ Esto puede verse claramente en las obras clásicas de la política comparada de los años 1920 y 1930, como lo son Democracias modernas de James Bryce (1921), Teoría y práctica del gobierno moderno de Herman Finer (1932), y Gobierno constitucional y política de Carl Friedrich (1937). Estos textos se enfocaron invariablemente en los Estados Unidos, el Reino Unido, Francia y Alemania, en algunos casos con miradas de reojo hacia Canadá y Australia y una referencia ocasional a Rusia. Por el contrario, aun en el trabajo de Bryce, uno de los pocos autores establecidos que había viajado a América del Sur, los veinte países de América Latina eran objeto de un análisis muy breve -estos países reciben atención en 21 páginas de una obra de 1.117 páginas (Bryce, 1921: Vol. 1, Cap. 17)- que los presentaba esencialmente como casos contrastantes, es decir, como casos en que las condiciones para la democracia encontradas en los casos más conocidos estaban ausentes (Bryce, 1921: Vol. 1, 188). Antes de la Segunda Guerra Mundial, el estudio de la política comparada era un asunto bastante parroquial.

El estatus del estudio de la política latinoamericana, y el alcance empírico de la política comparada, cambiaron considerablemente como resultado de la nueva literatura sobre la modernización y la dependencia en las décadas de 1950 y 1960. La literatura de la modernización incorporó a América Latina, así como a Asia y África, a los debates generales de política comparada. Y, en un quiebre aun más significativo con respecto de los patrones anteriores, el pensamiento sobre América Latina durante este período comenzó a ser influenciado por autores que vivían en la región -estos autores eran principalmente sociólogos, ya que en ese tiempo la ciencia política era prácticamente inexistente en América Latina ${ }^{2}$ - que tenían un conocimiento más cercano de la política de América Latina que sus homólogos de EE.UU., y que desarrollaron una visión

1 Para reseñas generales en el ámbito de la política comparativa, un campo que tomó cuerpo primero en los Estados Unidos, véase Eckstein (1963) y Munck (2009); sobre el estudio de la política latinoamericana, véase Valenzuela (1988) y Drake y Hilbink (2003).

2 Acerca de la institucionalización relativamente tardía de la ciencia política en América Latina, véase Altman (2006) y Huneeus (2006). 
alternativa a la perspectiva de la política latinoamericana que ofrecía la literatura de la modernización.

Las diferencias entre la teoría de la modernización y sus alternativas eran muy notables. ${ }^{3}$ Gran parte de la literatura de la modernización sobre América Latina consistía en aplicaciones del marco estructural-funcional desarrollado por Gabriel Almond sin conocimiento previo de América Latina (Almond y Coleman, 1960), o análisis que, siguiendo a Seymour Lipset (1959a), un autor que era conocedor de América Latina, asumían acríticamente que la modernización económica se despliega de la misma manera y con las mismas consecuencias políticas en todo el mundo. Por el contrario, Gino Germani (1962) ofreció una conceptualización que llamó la atención sobre el modelo específico de política que estaba asociado con el proceso de desarrollo económico de las sociedades latinoamericanas. Y teóricos de la dependencia como Fernando Cardoso y Enzo Faletto (1969) hacían hincapié en cómo la posición diferente dentro del sistema económico internacional de los países latinoamericanos, en comparación con los EE.UU. y Europa Occidental, llevó a un modelo diferente de desarrollo en América Latina y cómo este modelo diferente de desarrollo estaba asociado a una política diferente. En resumen, durante los años 1950 y 1960 se dio un interesante debate, en el cual los autores latinoamericanos pusieron en tela de juicio la ortodoxia de la teoría de la modernización y ofrecieron sus propias conceptualizaciones y teorizaciones. Y este debate contribuyó a transformar la política comparada en los EE.UU. de un asunto parroquial a una empresa de alcance mundial y a impulsar el estudio de la política latinoamericana.

El despegue real del estudio de la política latinoamericana, que la estableció firmemente como parte de la política comparada, se produjo sin embargo en la década de 1970, en gran parte impulsado por el análisis del quiebre de la democracia en América del Sur del politólogo argentino entrenado en Yale Guillermo O’Donnell (1973). ${ }^{4}$ El trabajo de O'Donnell provocó un animado intercambio entre los autores estadounidenses que estudiaban América Latina y autores latinoamericanos (Collier, 1979), dando un ejemplo de colaboración académica entre el Norte y el Sur que transformó la manera en que el conocimiento de la política latinoamericana era producido. Además, el trabajo de O’Donnell y la discusión al respecto fue fundamental, ya que dio impulso a una nueva agenda de investigación centrada en los regímenes políticos y la democracia en América Latina que ha sido mantenida durante las últimas cuatro décadas.

Esta agenda de investigación ha abordado varias cuestiones y ha sido avanzada por las contribuciones de un gran número de estudiosos. Por lo tanto, es difícil de caracterizar. Pero, como punto de entrada a este programa de investigación, tres rasgos merecen ser destacados. ${ }^{5}$ En primer lugar, una preocupación central de este programa de investigación ha sido la comprensión de la situación cambiante de la política en América Latina en

Para una reseña general de la literatura de la modernización y la dependencia sobre América Latina, véase Valenzuela y Valenzuela (1978).

4 Sobre la importancia de este trabajo de O'Donnell y el carácter decisivo del debate que generó, véase Touraine (1987: 4-12).

5 Para una caracterización más detallada de esta agenda, véase Munck (2007a). 
sus propios términos. A grandes rasgos, esta agenda de investigación se ha centrado en el quiebre de la democracia durante la década de 1970, la transición a la democracia en la década de 1980, la consolidación de la democracia en la década de 1990, y la calidad de la democracia en la década de 2000. Esto es, la motivación central de esta agenda de investigación ha sido la comprensión de la realidad política latinoamericana y las formas más sobresalientes que ha tomado la cuestión de la democracia en la región durante las últimas décadas.

En segundo lugar, aunque los estudiosos que han trabajado sobre esta agenda han mostrado una preocupación constante en relación a los problemas de la conceptualización y han participado en debates conceptuales -un aspecto particularmente sobresaliente de la investigación actual sobre la calidad de la democracia-, también han logrado desarrollar un acuerdo considerable acerca de muchas cuestiones conceptuales básicas. En concreto, en lugar de tomar las dimensiones macro de la política como constantes y centrarse sólo en las variaciones dentro de un determinado régimen o dentro de las democracias, como es común en gran parte de la política comparada, estos investigadores comparten un interés en variaciones al nivel macro relacionadas a los regímenes políticos y la democraticidad de los países latinoamericanos. Aún más, estos investigadores han convergido en gran parte en una conceptualización de los regímenes políticos en términos de los procedimientos que regulan el acceso a los más altos cargos políticos en un país y de la democracia como, al menos, un tipo de régimen caracterizado por el sufragio masivo y la competencia electoral (Dahl, 1971; Mazzuca, 2007).

En tercer lugar, esta agenda de investigación ha puesto un fuerte énfasis en las teorías explicativas y ha tratado de desarrollar teorías de una manera abiertamente cosmopolita, es decir, a través de un diálogo con las teorías existentes sobre otras regiones del mundo, especialmente los Estados Unidos y Europa. De hecho, en este sentido, es importante recordar que la comunidad de estudiosos que han contribuido a esta agenda han sido latinoamericanistas de América Latina, Estados Unidos y Europa, pero también comparativistas amplios -esto es, especialistas en política comparadaque han trabajado más en otros países (por ejemplo, Estados Unidos en el caso de Lipset, países europeos en el caso de Alain Touraine, Juan Linz y Philippe Schmitter) o que han estudiado América Latina desde una perspectiva global (por ejemplo, Adam Przeworski). Ésta ha sido una característica muy distintiva, que le ha dado un vigor notable a la literatura.

Recapitulando, el estudio de la política latinoamericana ha dado pasos importantes en los últimos cuarenta años. Se ha forjado una verdadera agenda de investigación sobre regímenes políticos y democracia en América Latina compartida por un grupo de distinguidos estudiosos de la política. Esto es, se ha tomado la realidad política de América Latina, o al menos algunos de los aspectos de la realidad política de gran valor normativo, como objetos para ser estudiados de forma sistemática. Y, como veremos a continuación, se ha generado una rica discusión sobre cómo explicar la variada experiencia con la democracia y otros regímenes políticos en América Latina. 


\section{TEORÍAS EXPLICATIVAS SOBRE REGÍMENES Y DEMOCRACIA: IDEAS, DEBATES Y HALLAZGOS}

Las principales teorías explicativas en la literatura sobre regímenes y democracia en América Latina se han centrado en dos preguntas que están estrechamente relacionadas pero que es útil considerar por separado: 1) ¿Cuáles son las condiciones para una transición de alguna forma de autoritarismo a la democracia? y 2) ¿Cuáles son los factores que explican la durabilidad de la democracia? Y, es importante notar que el florecimiento de debates acerca de estas dos preguntas ha sido posible porque, a pesar de que la cuestión de cómo definir la democracia sigue siendo materia de mucha discusión, el consenso amplio de que la democracia es, al menos, un tipo de régimen en el cual el acceso a los más altos cargos públicos en un país se caracteriza por el sufragio masivo y la competencia electoral ha ofrecido un punto de referencia ampliamente compartido. En otras palabras, es fundamental tener en cuenta que el consenso en relación a un concepto básico para esta agenda de investigación ha servido como un ancla conceptual suficientemente sólida para una serie de debates muy fértiles sobre teorías explicativas.

De todas formas, aun cuando la democracia es definida en términos minimalistas, no es un asunto simple proveer una evaluación comprensiva de los debates sobre la democracia. Las teorías explicativas varían en función de su objetivo, algunas teniendo por objeto ofrecer una respuesta tanto a la cuestión de los orígenes como de la durabilidad de la democracia, otras centrándose en una sola de estas preguntas. Las explicaciones varían también en términos de su parsimonia, algunas de ellas destacando el impacto de una sola variable, mientras que otras postulan múltiples variables; y en términos de su claridad, es decir, si las hipótesis se especifican con precisión. Por último, las explicaciones varían en función del grado en que han sido objeto de rigurosas pruebas. No obstante, esta literatura amplia y a veces un tanto dispar ha generado líneas discernibles de investigación teórica y empírica que pueden ser resumidas bajo cinco encabezamientos: i) la tesis de la modernización económica, ii) las teorías culturales, iii) las teorías sobre el desarrollo capitalista y las clases sociales, iv) los modelos de coyuntura crítica, y v) las teorías político-institucionales. ${ }^{6}$

\subsection{Tesis de la Modernización Económica}

Uno de los debates iniciales en la literatura sobre regímenes y democracia en América Latina se enfocó en la tesis de Lipset (1959a), un teórico de la escuela de la modernización, que plantea que el desarrollo económico, entendido prácticamente como sinónimo del aumento en el nivel de ingresos en un país, aumenta la probabilidad de i) una transición a la democracia, y ii) la durabilidad de la democracia. Se han propuesto diferentes argumentos para explicar por qué se espera que el desarrollo económico tenga un efecto

6 Estas líneas de investigación no son puramente independientes entre sí, y académicos que trabajan en una línea de investigación con frecuencia toman prestado de otras líneas de investigación. Sin embargo, como la discusión que sigue trata de mostrar, es útil organizar una revisión de la literatura usando estos cinco encabezamientos. 
positivo sobre la democracia (por ejemplo, su impacto en la cultura, la estructura de clases, etc.). Y estos argumentos han sido objeto de diversos debates, que trato más adelante. Para empezar, sin embargo, revisaré el debate acerca de la afirmación central de la teoría de la modernización: la tesis de Lipset.

La discusión inicial de la tesis de Lipset se produjo en el contexto de la ola de quiebres de la democracia en América Latina durante los años 1960 y 1970 y se centró en el desafío directo de O'Donnell (1973) a la segunda parte de la tesis de la modernización, sobre la durabilidad de la democracia. Basándose en ideas sobre el desarrollo económico en América Latina elaboradas por Albert Hirschman (1968), O’Donnell postuló que en lugares como América del Sur el proceso de desarrollo económico no había replicado el proceso de las economías avanzadas y había dado lugar a un mayor nivel de conflictos sociales, y que estos conflictos habían sido resueltos de una manera que socavaba la democracia. Esta tesis de la modernización también fue cuestionada, de una manera diferente, por Linz (1975: 182), quien hizo hincapié en la necesidad de comprender la dinámica política de los diferentes tipos de regímenes políticos y llamó la atención al propio proceso político y las decisiones de los actores políticos dentro de entornos institucionales (Linz, 1978, véase también Valenzuela, 1978). Es decir, mientras que O’Donnell cuestionó el vínculo entre el desarrollo económico y político planteado por la teoría de la modernización, pero no criticó el énfasis en causas económicas en la teoría de la modernización, Linz puso en duda la premisa más básica de que los factores económicos deben ser destacados a expensas de los factores políticos.

La primera parte de la tesis de la modernización, respecto de las transiciones a la democracia, fue el tema central de discusión en el contexto de la investigación sobre las transiciones a la democracia en América Latina durante las décadas de 1980 y 1990. Y, de nuevo, aun cuando algunos teóricos de la modernización comenzaron a referirse a un resurgimiento de la teoría de la modernización después de que ésta había perdido credibilidad en los años 1970, la literatura sobre América Latina fue en gran parte crítica de la tesis de la modernización. En particular, O’Donnell y Schmitter (1986: 3-5, 18-19) sugirieron que, aunque la durabilidad de la democracia podría estar fuertemente influenciada por factores económicos estructurales, las transiciones a la democracia son procesos más abiertos y contingentes. Pues, argumentaron, de una forma que recordaba el análisis de Linz (1978) sobre el quiebre de la democracia, que las decisiones estratégicas de los actores políticos y sociales pueden anteponerse a los prerrequisitos estructurales, incluyendo aquellos identificados en la tesis de Lipset (véase también Przeworski, 1991: Cap. 2).

Además de ser un punto de referencia estándar en los debates sobre regímenes y democracia en América Latina, la tesis de la modernización ha sido probablemente la hipótesis más sujeta a pruebas empíricas en la literatura cuantitativa. Estas pruebas tienen limitaciones importantes. Han utilizado simples medidas económicas como el PBI per cápita, que no capta el sentido más elaborado de desarrollo económico que ofrecen varios autores ni distingue entre las diversas fases del proceso de desarrollo. Estas pruebas también son constreñidas debido a la disponibilidad limitada de datos sobre otras variables, por lo 
cual ignoran completamente argumentos sobre las decisiones estratégicas de los actores y la interacción entre estructura y agencia. No obstante, es interesante que estas pruebas han dado algún apoyo a los argumentos contrarios a la tesis de la modernización que surgieron en los estudios sobre América Latina.

Las investigaciones realizadas por Przeworski (Przeworski y Limongi, 1997; Przeworski et al., 2000: Cap. 2, Przeworski, 2009), que incluyen los casos latinoamericanos junto con el resto del mundo, han apoyado el argumento de que niveles más altos de desarrollo económico están asociados con un riesgo reducido de quiebre de la democracia (en contra de O’Donnell, 1973) pero no con una mayor propensión a una transición a la democracia (de acuerdo con O'Donnell y Schmitter, 1986, y Przeworski, 1991). Y la investigación por Scott Mainwaring y Aníbal Pérez-Liñán (2003, 2005: 25-38), centrada exclusivamente en América Latina, debilita aún más la tesis de la modernización. En efecto, la investigación de Mainwaring y Pérez-Liñán refuerza el hallazgo de Przeworski sobre la falta de un vínculo entre el desarrollo económico y las transiciones democráticas. Pero estos autores también encuentran (en consonancia con O’Donnell, 1973) que, al menos en América Latina, niveles más altos de desarrollo económico están asociados con mayores perspectivas de un quiebre de la democracia y, por lo tanto, plantean la posibilidad de un excepcionalismo latinoamericano, esto es, de una divergencia entre las pautas que se encuentran en el análisis de América Latina con respecto a los análisis a nivel mundial (para una conclusión similar, vea Landman, 1999). La investigación estadística sobre el tema todavía está en curso. ${ }^{7}$ Sin embargo, en las últimas cuatro décadas la tesis de Lipset sobre las consecuencias políticas de la modernización económica ha sido debilitada por la investigación sobre América Latina. ${ }^{8}$

\subsection{Teorías Culturales}

Otro argumento sobre los orígenes y la durabilidad de la democracia que surge de la teoría de la modernización y, más concretamente, de la literatura de la cultura cívica (Almond y Verba, 1963), sostiene que un país transita a la democracia y perdura como una democracia en la medida en que sus habitantes tienen actitudes democráticas, es decir, apoyan un conjunto de valores que se consideran consistentes con el funcionamiento de la democracia y, por lo tanto, ven a los regímenes democráticos como legítimos y los regímenes no democráticos como ilegítimos. ${ }^{9}$ Este argumento cultural estándar suele estar vinculado explícitamente a la tesis de la modernización económica, en tanto que los teóricos de la modernización frecuentemente ven un cambio cultural como una variable interviniente entre la modernización económica y la democracia. Además, es

Véase, especialmente, Boix y Stokes (2003) y Acemoglu, Johnson, Robinson y Yared (2008).

Otra rama de este debate ha sido la discusión sobre la maldición de los recursos (resource curse) en América Latina, que es relevante para la tesis de la modernización en que se enfoca no sólo en un nivel agregado de desarrollo económico sino en la composición de las actividades económicas y los sectores de la economía que ganan prominencia (Karl 1997, Dunning 2008). Esta literatura ofrece un puente con la literatura sobre el desarrollo capitalista analizado a continuación y articula las consecuencias políticas de los factores económicos de una forma más directa y compleja que es estándar en la teoría de la modernización.

9 Aunque este argumento se centra en la cultura pública general, otros argumentos culturales que se abordan a continuación se centran en los valores de las clases sociales y las élites. 
similar a la tesis de la modernización económica en el sentido que identifica un factor que está afuera de la esfera política para dar cuenta de los orígenes y la durabilidad de la democracia. Pero se distingue del argumento sobre la modernización económica formulado por los defensores de la teoría de la modernización en que se centra en una variable micro en lugar de una a nivel macro.

Los estudiosos de los regímenes y la democracia en América Latina están bastante divididos en cuanto a las explicaciones culturalistas de la democracia y la tesis de la cultura cívica en particular. Muchos son bastante escépticos con respecto a dichas explicaciones y las han criticado en gran medida con argumentos esgrimidos por Brian Barry (1978: 48-52). Algunos de estos investigadores escépticos han puesto los argumentos culturales en la misma bolsa que la tesis de la modernización económica y los ven como pasando por alto el papel clave desempeñado por las interacciones entre élites y las instituciones políticas (O’Donnell y Schmitter, 1986). En contraste, sostienen que es posible tener "democracia sin demócratas," y que una cultura cívica es "mejor pensada como un producto y no como un productor de la democracia" (Schmitter y Karl, 1991: 83, traducción propia; Schmitter, 2009: 18). ${ }^{10}$

A su vez, otros autores han cuestionado los argumentos culturalistas como parte de un rechazo más amplio de un concepto individualista de la legitimidad, que es visto como ignorando que el cambio de régimen viene sólo a través de las acciones de las fuerzas políticas organizadas (Przeworski, 1986: 50-53, 1991: 28, 54). Discrepando con los argumentos culturalistas, estos autores sostienen que, al menos en lo que respecta a la durabilidad de la democracia, se puede ofrecer una explicación satisfactoria con base en factores económicos e institucionales, y en los intereses en particular, y que no hay necesidad de recurrir a la cultura y a los valores (Przeworski, Cheibub y Limongi, 2004; véase también Przeworski, 2006: 324-26).

Pero para muchos estudiosos los argumentos culturalistas tienen un atractivo teórico considerable. Aunque se enfocaba inicialmente en Europa, Ronald Inglehart (1990) lanzó una defensa de la tesis de la cultura cívica. Y, relacionadamente, otros reconocidos investigadores y teóricos de la democracia declararon la "centralidad de la cultura política" y que "la democracia requiere una cultura que la sustente" (Lipset, 1994: 3); que la democratización y la durabilidad de las democracias depende "en gran medida de dos factores," uno de ellos siendo la cultura (Huntington, 1997: 4-5), y que "la cultura política -en particular, las creencias acerca de la legitimidad democrática- [es] un factor central en la consolidación de la democracia" (Diamond, 1999: 162, traducción propia). ${ }^{11}$ Por lo tanto, la importancia de la cultura en el origen y la durabilidad de la democracia es una cuestión muy debatida.

10 Esta línea de análisis es similar a la de Lijphart (1968), quien argumentó, en contra de Almond (1956), que la democracia es posible en sociedades culturalmente divididas si las élites políticas se ponen de acuerdo sobre ciertas instituciones políticas.

11 Linz y Stepan (1996: 6, traducción propia) dan un paso más allá y afirman que, por definición, una democracia no está consolidada a menos que “una gran mayoría de la opinión pública cree que la manera más apropiada para regir la vida colectiva en una sociedad es a través de procedimientos e instituciones democráticas". 
Pruebas rigurosas de los argumentos culturales se basan principalmente en datos de encuesta. Y, tanto por ser la recolección de datos de encuesta un desarrollo relativamente reciente en las ciencias sociales como porque estos datos son de por sí sospechosos cuando son recogidos en contextos no democráticos, los argumentos culturales sobre las transiciones a la democracia se han abordado sólo de manera indirecta. Sin embargo, esta investigación ha arrojado resultados interesantes. Parte del trabajo de esta investigación ha sido identificar los componentes de una cultura civil, es decir, las actitudes que son relevantes para una cultura cívica. Y, a medida que ha avanzado esta investigación, el vínculo entre la cultura cívica y la democracia ha sido abordado y algunas respuestas han ido ganando credibilidad.

Unos pocos autores, siendo Inglehart el más prominente, han mantenido firmemente que la democratización y la estabilidad de la democracia pueden ser explicadas en términos de factores culturales. ${ }^{12}$ Sin embargo, un estudio clave de Edward Muller y Mitchell Seligson (1994: 646-47, traducción propia), que rompió con el sesgo eurocéntrico de la investigación por encuestas mediante la inclusión de seis países de América Central, rechazó "la tesis de que las actitudes de una cultura cívica son la principal o incluso una de las causas mayores de la democracia" y sostuvo, en cambio, que las actitudes fundamentales de una cultura cívica, como la confianza interpersonal, son "un producto de la democracia en lugar de una causa de la misma". Además, los resultados de las investigaciones en curso de Inglehart han sido cada vez más cuestionados. ${ }^{13}$

Así pues, aunque algunos autores siguen abogando por una versión actualizada de la tesis de la cultura cívica, frente a los débiles resultados, otros estudiosos que analizan la cultura han reorientado su análisis. De hecho, el análisis de John Booth y Seligson (2009), utilizando datos de encuesta de ocho países de América Latina, propone "explicar la desconcertante ausencia de un efecto de la legitimidad sobre los regímenes" (Booth y Seligson, 2009: 1, 237, traducción propia). Esto es, en vez de preguntarse acerca del impacto de la legitimidad sobre la democracia, en un giro significativo Booth y Seligson toman la falta de efecto de la legitimidad sobre la durabilidad de la democracia como el punto de partida de la investigación.

En resumen, a pesar de que los investigadores de encuestas en particular no han abandonado la búsqueda de efectos de la legitimidad y los posibles vínculos entre la legitimidad y la durabilidad de la democracia, ${ }^{14}$ la evidencia empírica ha estado principalmente del

12 De hecho, Inglehart argumentó en sus primeros trabajos que una cultura cívica aumenta la probabilidad de que la democracia perdure (Inglehart 1990) y ha suscrito consistentemente a una explicación culturalista fuerte de los orígenes y la durabilidad de la democracia (Inglehart y Welzel 2005: 9, Cap 8).

13 Para críticas del trabajo reciente de Inglehart, véase Hadenius y Teorell (2005), Teorell y Hadenius (2006), Booth y Seligson (2009: 11), y Fails y Pierce (2010).

14 Tras articular cuidadosamente lo que quieren decir por legitimidad y tras proponer una medida multidimensional de la legitimidad, Booth y Seligson (2009) consideran el impacto de la legitimidad sobre las actitudes y los comportamientos de los ciudadanos. A pesar de que no se centran en hechos relacionados directamente con el quiebre de la democracia, avanzar el argumento de que la falta de legitimidad podría proporcionar un terreno fértil para las élites que quisieran socavar la democracia e, interesantemente, sugieren que, sobre la base del análisis de los ocho países que estudiaron utilizando datos de 2004, están preocupados por las perspectivas de la sobrevivencia de la democracia en Honduras-Guatemala también está señalada como un 
lado de los críticos de los argumentos culturalistas. ${ }^{15}$ Las creencias de la población en general acerca de la legitimidad de la democracia no son, en sí mismas, un factor clave, ni en las transiciones a la democracia ni en la durabilidad de la democracia.

\subsection{Teorías del Desarrollo Capitalista y las Clases Sociales}

Una tercera línea de investigación en la literatura sobre regímenes y democracia en América Latina, que tiene algunos vínculos con las dos anteriores, se centra en la naturaleza del proceso de desarrollo económico, rastrea el impacto del desarrollo económico sobre la estructura social, y luego conecta diferencias en la estructura social con las perspectivas de alcanzar y mantener la democracia. La tesis central de esta literatura, sobre la cual hay un amplio grado de acuerdo, es que una clase específica de desarrollo económico, el desarrollo capitalista, está asociada con la democracia porque fomenta el fortalecimiento de las clases sociales que pueden ofrecer un contrapeso al Estado y que probablemente luchen por la representación política. En breve, el capitalismo es comúnmente considerado una condición necesaria, aunque no suficiente, de la democracia. No obstante, ha habido un debate acerca de qué clases sociales, y qué configuraciones de clases, son más conducentes a la democracia.

Sucintamente, en cuanto al origen de la democracia, la visión estándar de los teóricos de la modernización, avanzada tanto en análisis mundiales (Lipset, 1959a: 83, 85) como en trabajos sobre América Latina (Johnson 1958), es que el desarrollo capitalista promueve la democracia porque crea una clase media y porque la clase media es un promotor fundamental de la democracia. Además, los teóricos de la modernización han declarado que la clase obrera es la clase con las actitudes más extremistas y autoritarias; ${ }^{16}$ por lo tanto, estos teóricos sostienen que la democracia requiere de una clase media fuerte y una clase trabajadora débil. Pero otros argumentos han sido propuestos también. A pesar de que Barrington Moore (1966: Cap. 7) no incluyó América Latina en su análisis, su argumento de que el desarrollo capitalista conduce a la democracia en la medida en que lleva al empoderamiento de una burguesía urbana a expensas de la clase alta terrateniente, se convirtió en un punto de discusión en la literatura sobre los orígenes sociales de la democracia en América Latina. Y Dietrich Rueschemeyer, John Stephens

caso preocupante (Booth y Seligson 2009: 150, 220, 241-57). Habida cuenta de que el libro de Booth y Seligson se publicó en febrero de 2009 y que el Presidente Zelaya de Honduras fue desplazado del poder en junio de 2009, bien puede haber algo en el argumento sobre la importancia de las creencias del público general.

15 Una literatura relacionada se ha centrado en la religión. Por ejemplo, Lipset (1959a: 65, 92-93) argumentó que el protestantismo es propicio para el desarrollo de valores democráticos, pero que el catolicismo no tiene un efecto similar. Sin embargo, una prueba preliminar, sobre la base de una simple distinción entre países protestantes, católicos y musulmanes, no encuentra impacto de la cultura entendida de este modo ya sea en la probabilidad de una transición a la democracia como en la durabilidad de la democracia (Przeworski, Cheibub y Limongi 2004). Para más evidencia empírica en contra de las teorías culturales, véase Valenzuela y Valenzuela (1983: 15-22).

16 Gran parte de la literatura de la escuela de la modernización sobre la base de clase de la democracia se vincula con una teoría culturalista. Por ejemplo, Lipset (1959a: 83, 89, 1950b: 482) sostuvo que el fortalecimiento de una clase media es favorable a la democracia porque los miembros de la clase media se caracterizan por un punto de vista político moderado que contrarresta los valores extremistas y autoritarios de la clase obrera, vista por Lipset como teniendo actitudes más extremistas y autoritarias que las clases medias y altas. 
y Evelyne Huber Stephens (1992: 40-63, véase también Therborn, 1977) añadieron una nueva perspectiva al debate con su argumento de que la democracia depende del empoderamiento de la clase obrera relativo a la burguesía.

Las teorías del desarrollo capitalista y las clases sociales no han sido sometidas al mismo grado de escrutinio a través de análisis cuantitativos como las tesis de la modernización sobre el nivel de desarrollo económico y la cultura cívica. Pero la investigación empírica sobre América Latina arroja algo de luz sobre la validez de estas teorías. La tesis general sobre la relación entre el capitalismo y la democracia ha recibido apoyo en el estudio de Touraine (1989) sobre América Latina durante el período 1930-1980. De hecho, elaborando una línea de análisis que se puede remontar a un libro clásico de la teoría de la dependencia (Cardoso y Faletto, 1969), Touraine muestra que a pesar de que el desarrollo económico fue de naturaleza capitalista en las sociedades dependientes de América Latina, no fue dirigido por una burguesía nacional. Y, como es de esperarse, las clases sociales fueron menos independientes del Estado, el impulso a la democracia fue más débil, y las democracias que surgieron son mejor caracterizadas como democracias de masas que como democracias representativas. ${ }^{17}$

En cuanto a los argumentos más específicos sobre las clases sociales, la evidencia no ha producido una generalización robusta. De acuerdo al resumen por Peter Smith (2005: 55-62, traducción propia; véase también Drake, 2009: 10-13) de una amplia literatura, ${ }^{18}$ en "1900-1939, la democratización fue adoptada por las élites tradicionales," es decir, la oligarquía terrateniente; durante "1940-1977, las clases medias realizaron demandas efectivas para el cambio democrático;" y durante 1978-2000, los sindicatos obreros y las clases medias fueron factores clave en la transición hacia la democracia. Pero, complicando la cuestión aún más, hay evidencia de que la clase alta terrateniente y la burguesía urbana apoyaron regímenes autoritarios y respaldaron golpes militares con regularidad, de que la clase media apoyó golpes militares también, y de que la clase obrera dio respaldo a regímenes autoritarios. ${ }^{19}$ De hecho, es justo decir que ninguna de las teorías que sostienen que una sola clase es la portadora fundamental de la democracia o el principal obstáculo para la democracia ha recibido un fuerte apoyo empírico.

Una de las razones para la falta de apoyo a las teorías de clase de la democracia es, como argumenta Samuel Valenzuela (2001), que estas teorías padecen de una deficiencia teórica (véase también Valenzuela y Valenzuela, 1983: 27-29, 36). Como muestra Valenzuela (2001), el registro histórico de Chile no sólo no concuerda con la afirmación de Moore acerca de la postura antidemocrática de la élite terrateniente, ya que las reformas que colocaron a Chile en una vía democrática a principios del siglo XIX fueron impulsadas por las élites conservadoras vinculadas con la clase terrateniente tradicional. Más importante aún, como señala Valenzuela, el ímpetu detrás de estas reformas fue el deseo de las élites

17 Para una actualización de esta línea de análisis, véase Garretón et al. (2004).

18 Véase Therborn (1979), Rueschemeyer, Stephens y Stephens (1992), Huber y Safford (1995), Drake (1996), y Collier (1999).

19 Véase Nun (1967), O’Donnell (1978), Baloyra-Herp (1983), Bartell y Payne (1995), Paige (1997), Middlebrook (2000), y Levitsky y Mainwaring (2006). 
políticas conservadoras de obtener una ventaja sobre las élites liberales. Esto es, lo que muestra Valenzuela es que todos los análisis de clase son deficientes dado que ignoran el papel de las élites políticas y, en particular, las divisiones posibles y la competencia entre estas élites.

En suma, la investigación sobre América Latina apoya el argumento general de que el capitalismo es una condición necesaria pero no suficiente de la democracia. Pero no ha prestado apoyo a las múltiples hipótesis sobre clases específicas. Y ha generado una importante crítica teórica de los análisis de clase, la falta de atención al papel de las élites políticas.

\subsection{Modelos de Coyuntura Crítica}

Un cuarto cuerpo de literatura sobre regímenes y democracia en América Latina se ha basado en un modelo de coyuntura crítica y ha presentado una familia de argumentos que se basan en este modelo. Una característica distintiva de estos modelos es que explican desarrollos políticos en términos de los legados de eventos que se produjeron muchas décadas en el pasado en lugar de postular causas y efectos que están cerca en el tiempo, como es más habitual en las teorías expuestas anteriormente. Otra característica clave es que los modelos de coyuntura crítica, aunque invocando variables económicas y sociales, suelen incorporar variables políticas como factores explicativos centrales y por lo tanto proponen teorías que sistemáticamente reconocen la autonomía de la política. Así, aunque la literatura sobre coyunturas críticas es muy diversa, introduce una ruptura significativa con respecto a las tres líneas de investigación discutidas anteriormente y ofrece una alternativa a las teorías societales a través de su énfasis en explicaciones históricas y políticas.

El primer análisis de coyunturas críticas en América Latina fue el libro de Ruth Berins Collier y David Collier (1991), Shaping the Political Arena [Forjando la arena politica]. ${ }^{20}$ Este libro argumenta que el quiebre de las democracias en las décadas de los años 1960 y 1970 podía atribuirse a la dinámica de los sistemas de partidos que fueron forjados por los eventos más o menos en las décadas de los años 1920 y 1930, cuando decisiones políticas -determinadas a su vez por el poder de la oligarquía en relación con los reformadores de clase media- fueron tomadas con respecto a la incorporación de la clase obrera a la arena política nacional. Este libro sigue siendo, veinte años después de su publicación, el mejor y más claramente argumentado análisis de coyunturas críticas en América Latina. Pero este libro también abrió un debate que está en curso.

El debate en la literatura sobre coyunturas críticas gira, en gran medida, en torno a qué evento clave es visto como el determinante de la dinámica de los regímenes en América Latina durante la segunda mitad del siglo XX y cuán remotas en el tiempo están las raíces

20 Aunque la literatura más amplia sobre coyunturas críticas en la política comparada fue iniciada en gran parte por Lipset y Rokkan (1967), la formalización explícita de este tipo de explicación por Collier y Collier (1991: Cap. 1) estimuló una discusión más explícitamente teórica y metodológica sobre el modelo de coyunturas críticas. 
de estos regímenes. ${ }^{21}$ De hecho, aunque muchos autores hacen hincapié en la incorporación de la clase obrera o, más ampliamente, la respuesta política a la cuestión social durante el segundo cuarto del siglo XX,22 como hacen Collier y Collier (1991), otros se enfocan en varios eventos hito ocurridos con anterioridad. Por ejemplo, algunos autores sugieren que los orígenes de los regímenes en América Latina durante el siglo XX se encuentran en las reformas liberales de fines del siglo XIX (Mahoney, 2001). A su vez, otros ven la formación del Estado durante el siglo XIX como el principal evento formativo (LópezAlves, 2000). Y aún otros plantean que la perspectiva de la democracia en América Latina en el siglo XX fue en gran parte determinada por la experiencia colonial y, en particular, por la cultura ibérica de España y Portugal traída a las Américas y transferida a las élites latinoamericanas (Lipset y Lakin, 2004: Caps. 10 y 11). ${ }^{23}$

Ésta es una literatura rica, variada y sugerente. Sin embargo, sus conclusiones siguen siendo inciertas. Por un lado, los distintos argumentos que se han presentado en esta literatura no siempre han sido claramente vinculados a los orígenes y la durabilidad de la democracia. Por otra parte, estos argumentos no han sido sometidos a pruebas empíricas sistemáticas. De hecho, usualmente los argumentos sobre coyunturas críticas han sido desarrollados inductivamente y no han sido probados en el contexto de casos nuevos. Además, simplemente carecemos de pruebas de diferentes argumentos basados en un modelo de coyuntura crítica y de los argumentos basados en un modelo de coyuntura crítica en comparación con los otros argumentos en la literatura sobre regímenes y democracia que han sido discutidos en este artículo. Por lo tanto, es importante reconocer que aún no podemos pronunciarnos sobre el debate interno entre autores que usan un modelo de coyuntura crítica y tampoco sobre la crítica teórica al pensamiento más convencional sobre la democracia presentada por el análisis de coyunturas críticas.

\subsection{Teorías Político-Institucionales}

Una quinta línea de investigación sobre regímenes y democracia en América Latina coloca de lleno la atención en los agentes de la política, es decir, los actores que participan en actividades políticas y toman decisiones políticas, y en las instituciones políticas diseñadas por los actores políticos y que, a su vez, facilitan y constriñen la acción política rutinaria. Esta investigación, como la literatura sobre coyunturas críticas, se distingue de las teorías que ven las causas de los regímenes y la democracia solamente en factores societales -un elemento común en las hipótesis de la teoría de la modernización sobre el desarrollo económico, la cultura cívica y las clases sociales- y reconoce la autonomía de la política. Pero las teorías político-institucionales suelen ir más allá de la literatura sobre coyunturas críticas al poner un acento en características de las élites políticas y la dinámica de la esfera política propiamente dicha.

Otra cuestión que ha sido recientemente debatida es si las reformas neoliberales implementadas en América Latina durante los años 1980 y 1990 constituyen una nueva coyuntura crítica. Véase, entre otros, Collier y Handlin (2009) y Tanaka (2009).

22 Mouzelis (1986), Waisman (1987), Scully (1992), Yashar (1997), Munck (2002).

23 Véase también Morse (1964), Véliz (1980), y Wiarda (2001). 
Esta línea de investigación se centró inicialmente en el impacto sobre las transiciones democráticas de los gobernantes y las instituciones no democráticas. La teoría más ambiciosa fue desarrollada por Linz (1975, Linz y Stepan, 1996: Caps. 3 y 4, 66-71), quien propuso una tipología de todos los regímenes políticos del siglo XX y formuló la hipótesis de que la dinámica política de cada régimen afecta a las perspectivas de una transición a la democracia. Relacionadamente, el modelo del proceso político de transición democrática desarrollado por O’Donnell y Schmitter (1986) puso de relieve que, dado un determinado tipo de régimen no democrático, una transición a la democracia depende de las decisiones estratégicas de los actores, tales como aceptar un pacto sobre algunas cuestiones políticas fundamentales. Y elaborando este tipo de análisis, estudios más estrechos teorizaron sobre las perspectivas de democratización en la amplia gama de regímenes no democráticos en América Latina durante el siglo XX, regímenes caracterizados como burocráticos autoritarios (O'Donnell, 1979, 1982; Rouquié, 1984: Caps. 8 y 9; Munck, 1998), sultanísticos (Chehabi y Linz, 1998; Snyder, 1998), de partido dominante (Magaloni, 2006; Greene, 2007) y autoritarios movilizacionales (Pérez-Stable, 1998).

Otra rama de estos estudios abordó las perspectivas de la durabilidad de las democracias. Una hipótesis que ha sido objeto de debate desde que los países de América Latina retornaron a la democracia en los años 1980 y 1990 fue que el modo de transición de un régimen no democrático afecta las perspectivas de la consolidación de la democracia y que las transiciones negociadas o pactadas son el modo más propicio de transición (Karl, 1990, Munck y Leff, 1997). Aún más atención se centró en las instituciones políticas diseñadas en el curso de una transición a la democracia. Una vez más Linz enmarcó gran parte del debate. Ampliando un punto introducido en el modelo del proceso político de quiebre de la democracia que había formulado en la década de 1970 (Linz, 1978: 71-74), Linz (1994, Linz y Valenzuela, 1994) desarrolló la tesis de que las democracias presidenciales tienen menos probabilidades de perdurar que las democracias parlamentarias. Y, suplementando esta tesis, otros alegaron que el presidencialismo es especialmente problemático cuando está asociado con un sistema multipartidista fragmentado (Mainwaring, 1993; Hartlyn y Valenzuela, 1994: 114).

Las hipótesis en la literatura político-institucional han recibido diferentes grados de apoyo empírico. Varias pruebas se han enfocado en la durabilidad de los diferentes tipos de regímenes no democráticos. Barbara Geddes (2003: 69-85) ha demostrado que los regímenes de partido único son los más duraderos, los regímenes militares los menos duraderos, mientras que los regímenes personalistas constituyen un tipo intermedio. Un estudio de la durabilidad en sus cargos de líderes individuales, una cuestión algo diferente a la durabilidad del régimen, demuestra que los gobernantes no democráticos duran más cuando han logrado incorporar partidos algo autónomos dentro de una legislatura (Gandhi y Przeworski, 2007: 1290-91; Gandhi, 2008: Cap. 6). Y estudios empíricos también han demostrado que la razón por la cual los sistemas de partido dominante perduran tanto como lo hacen es debido a la asimetría de recursos, es decir, el uso de los recursos públicos con fines partidarios por parte de los titulares de cargos públicos (Greene, 2010: 817-20). Por lo tanto, la hipótesis general de que los 
gobernantes y las instituciones no democráticas afectan las perspectivas de las transiciones democráticas ha recibido algún respaldo.

En cuanto a las hipótesis acerca de la durabilidad de la democracia, una prueba preliminar, utilizando datos de Europa y América Latina durante el período 1974-2000, no ofrece un fuerte apoyo para el argumento de que los modos de transición, y en particular las transiciones pactadas, tienen un impacto en la consolidación de la democracia (Schneider, 2009: Cap. 7). Pero un análisis empírico más amplio, que abarca todas las transiciones democráticas en casi 150 países desde 1900, respalda la hipótesis de que las transiciones a través de pactos están asociadas con una mayor durabilidad de la democracia (Stradiotto, 2009).

A su vez, como muestra José Antonio Cheibub (2007: 2), el registro histórico de todos los regímenes democráticos en el mundo entre 1946 y 2002 confirma que las democracias presidenciales no han durado tanto como las democracias parlamentarias. Pero, como Cheibub (2007: Cap. 6) también afirma, un análisis de los datos muestra que esto no es así debido a las características institucionales del presidencialismo, sino más bien porque las democracias presidenciales han surgido en los países con una mayor propensión hacia las intervenciones militares, un fenómeno particular de América Latina. Además, aunque los presidentes minoritarios son frecuentes en las democracias presidenciales, como temían aquellos que ven el presidencialismo y el multipartidismo fragmentado como una combinación particularmente perniciosa, ha sido demostrado que la formación de gobiernos de minoría no tiene impacto alguno sobre la supervivencia de las democracias presidenciales (Cheibub, 2002: 294-302, 2007: 95-98).

En resumen, la perspectiva distintiva sobre los regímenes y la democracia en América Latina que ofrecen las teorías político-institucionales ha generado una amplia literatura. Y esta literatura tiene el mérito indiscutible de enfocarse en la esfera política propiamente dicha y de buscar causas políticas de cuestiones políticas. Sin embargo, aunque la minuciosidad de las pruebas empíricas ha variado considerablemente, estas pruebas revelan un apoyo mixto para las teorías político-institucionales.

\section{LAS FRONTERAS DE LA INVESTIGACIÓN: PREGUNTAS VIEJAS Y NUEVAS}

La visión general de los estudios sobre regímenes y democracia en América Latina que presenta este artículo arroja un saldo muy positivo. Una vasta literatura ha abordado un tema político clave y dado pasos importantes. Ha contribuido a los debates teóricos, algunas veces a través de críticas a las teorías desarrolladas fuera de la región, otras veces mediante la propuesta de nuevas teorías. Y ha contribuido a la comprobación empírica de teorías, a veces a través del estudio de los países latinoamericanos por sí mismos, otras veces a través del análisis de los países latinoamericanos junto con países de otras regiones. De hecho, desde la década de 1970 la agenda de investigación sobre regímenes y democracia en América Latina no solo ha generado muchos conocimientos sobre las realidades políticas latinoamericanas. Además, ha ofrecido una perspectiva 
latinoamericana -en contraposición a un mero punto de contraste para ideas formuladas en el contexto de las sociedades ricas- sobre los debates convencionales dentro de la política comparada y ha ayudado a hacer de la política comparada una empresa genuinamente mundial.

Al mismo tiempo, algunos grandes desafíos quedan por resolver en el estudio de regímenes y democracia en América Latina. La articulación de forma explícita de estos desafíos y la confrontación directa de estos desafíos es clave. En efecto, una agenda de investigación progresa solo en la medida en que hace frente a los desafíos nuevos que van surgiendo en el curso de la investigación. Pues, a modo de conclusión, ofrezco mi visión acerca de las fronteras de la investigación actual sobre la democracia en América Latina.

Un primer conjunto de desafíos se refieren a las preguntas viejas sobre los orígenes y la durabilidad de la democracia, definida en términos minimalistas, que han sido discutidas en este artículo. En cuanto a la teorización, es necesario seguir trabajando para formular teorías más claras, tanto en el sentido de especificar si se trata de explicar los orígenes y/o la durabilidad de la democracia, como de especificar si las teorías son complementarias o están en competencia. Relacionadamente, es necesario desarrollar teorías que no estén formuladas simplemente en términos de tal o cual variable, una forma de hacer teoría que está llevando a la postulación de un número cada vez mayor de las hipótesis posibles, ${ }^{24}$ y que en vez aborden de forma explícita cómo las diferentes variables interactúan y forman cadenas causales.

La organización de la literatura bajo cinco encabezamientos que propone este artículo ofrece un punto de partida para una discusión acerca de las diferencias y similitudes entre las múltiples explicaciones que se han propuesto. Pero, como el lector atento seguramente habrá notado, los argumentos presentados bajo estos cinco encabezamientos son en parte alternativos y en parte complementarios, esto es, de un estatus teórico algo incierto. Por lo tanto, el desarrollo de teorías más claras y fuertes requiere más trabajo tanto de desagregación y análisis como de integración y síntesis teórica. ${ }^{25}$

En lo que respecta a las pruebas empíricas, es importante superar algunas debilidades básicas de las pruebas existentes. Las pruebas más rigurosas, realizadas con técnicas estadísticas, han reflejado teorías algo libremente, tanto en el sentido de que se basan en datos que ofrecen pobres mediciones de los conceptos utilizados en las teorías como en el sentido de que han seguido la convención de evaluar el impacto de una variable a la vez aun cuando las teorías sugieren que las variables interactúan entre sí.

Aún más grave, aunque las pruebas se han centrado en gran medida en las hipótesis relacionadas con la teoría de la modernización, y cada vez más en argumentos institucionales, no contamos con pruebas sobre algunas hipótesis centrales -por ejemplo, no existe un estudio empírico riguroso sobre la base de clase de la democracia- y no se han comparado la gama completa de teorías - por ejemplo, nadie ha hecho un estudio

24 El problema de la teorización que conduce a una larga lista de variables independientes y de hipótesis es ilustrado por Diamond, Hartlyn y Linz (1999).

25 Para algunos intentos de síntesis, ver Mahoney y Snyder (1999) y Mazzuca (2010). 
comparando argumentos basados en un modelo de coyuntura crítica en relación a las varias hipótesis derivadas de la teoría de la modernización. Pues, es importante reconocer que en términos generales la literatura sobre regímenes y democracia en América Latina ha puesto más énfasis en la construcción de nuevas teorías que en poner a prueba estas teorías y, dado que la propuesta y el testeo de teorías son dos caras de una misma moneda, que es necesario poner más atención en el testeo de teorías acerca del origen y la durabilidad de la democracia.

Un segundo conjunto de desafíos se refiere al estudio de los aspectos de la democracia que van más allá de las características utilizadas en las definiciones minimalistas de la democracia, es decir, la elección de los líderes nacionales en elecciones libres y justas. La investigación sobre la democracia en un sentido amplio, o lo que ha sido frecuentemente llamado la calidad de la democracia (O'Donnell, Iazzetta y Vargas Cullell, 2003; O'Donnell, 2010), no fue tratado en este artículo por razones de espacio. Pero es pertinente concluir este artículo con unos comentarios breves al respecto.

Una razón para tratar cuestiones pertinentes a la calidad de la democracia en una agenda de investigación sobre la democracia es que la democracia no es una cuestión que sólo tiene que ver con la forma de acceso a los altos cargos del gobierno (Munck, 2007b). La política es, en esencia, una lucha sobre la dirección de la sociedad, y la democracia es, pues, un sistema en el que el pueblo tiene voz y voto, a través de las instituciones políticas, en las decisiones acerca de quién debe ocupar cargos gubernamentales de alto nivel y también hacia dónde se dirige una sociedad. Por lo tanto, aunque sigue siendo importante insistir en que la democracia entendida de forma minimalista -que, para evitar confusiones, debería llamarse democracia electoral- apunta a un valor básico, también es imperativo no reducir el estudio de la democracia a la democracia electoral.

Otra razón para pensar sobre la democracia en términos más amplios es que el debate político sobre la democracia en América Latina ha planteado esta necesidad (Munck, 2010). Como se mencionó en la introducción, a pesar de que algunas de las más dramáticas luchas en el proceso de democratización en América Latina se produjeron durante el siglo XX, sería un error suponer que la lucha por la democracia puede ser tomada como un asunto resuelto. En efecto, la transformación de las democracias que los latinoamericanos y las latinoamericanas hoy tienen en democracias más completas, es decir, democracias dotadas de poder político y de un poder político sometido al control democrático, se perfila como el próximo gran reto político de la región.

Así, junto con una reconsideración de preguntas viejas, anclada en una concepción minimalista de la democracia, la investigación sobre regímenes y democracia en América Latina también debería abordar otros aspectos de la democracia, que abren toda una serie de preguntas nuevas que requieren un trabajo conceptual, teórico y empírico. La historia de la democracia continúa desarrollándose. Y, continuando lo que se ha establecido como una tradición en el estudio de la política latinoamericana, los investigadores interesados en la política latinoamericana contemporánea deberían abocarse a la comprensión de la cuestión democrática del siglo XXI y a la producción de conocimientos que en alguna medida aporten al reto nuevo de democratizar la democracia. 


\section{REFERENCIAS}

Acemoglu, Daron, Simon Johnson, James A. Robinson y Pierre Yared. 2008. "Income and Democracy", American Economic Review 98 (3): 808-42.

Almond, Gabriel A. 1956. "Comparative Political Systems", Journal of Politics 18 (3): 391-409.

Almond, Gabriel y James Coleman (eds.). 1960. The Politics of the Developing Areas (Princeton, N.J.: Princeton University Press).

Almond, Gabriel y Sidney Verba (eds.). 1963. The Civic Culture: Political Attitutes and Democracy in Five Nations (Princeton, N.J.: Princeton University Press). [Versión en castellano: La cultura cívica. Estudio sobre la participación política democrática en cinco naciones (Madrid: Fundación FOESSA, 1970).]

Altman, David. 2006. "From Fukuoka to Santiago: Institutionalization of Political Science in Latin America", PS: Political Science \& Politics 39 (1): 196-203.

Baloyra-Herp, Enrique A. 1983. "Reactionary Despotism in Central America", Journal of Latin American Studies 15 (2): 295-319.

Barry, Brian. 1978. Sociologists, Economists and Democracy (Chicago: University of Chicago Press). [Versión en castellano: Los sociólogos, los economistas y la democracia (Buenos Aires: Amorrortu, 1974).]

Bartell, Ernest y Leigh A. Payne (eds.). 1995. Business and Democracy in Latin America (Pittsburgh: University of Pittsburgh Press).

Boix, Carles y Susan C. Stokes. 2003. “Endogenous Democratization”, World Politics 55 (4): 517-49.

Booth, John A. y Mitchell A. Seligson. 2009. The Legitimacy Puzzle in Latin America: Democracy and Political Support in Eight Nations (Nueva York: Cambridge University Press).

Bryce, James. 1921. Modern Democracies 2 Volúmenes (Nueva York: The Macmillan Company).

Cardoso, Fernando H. y Enzo Faletto. 1969. Dependencia y desarrollo en América Latina (México: Siglo XXI).

Chehabi, H.E. y Juan L. Linz (eds.). 1998. Sultanistic Regimes (Baltimore, Md.: The Johns Hopkins University Press).

Cheibub, José Antonio. 2002. "Minority Governments, Deadlock Situations, and the Survival of Presidential Democracies", Comparative Political Studies 35 (3): 284-312.

Cheibub, José Antonio. 2007. Presidentialism, Parliamentarism, and Democacy (Nueva York: Cambridge University Press).

Collier, David (ed.). 1979. The New Authoritarianism in Latin America (Princeton, N.J.: Princeton University Press). [Versión en castellano: El nuevo autoritarismo en América Latina (México: Fondo de Cultura Económica, 1985).]

Collier, Ruth Berins. 1999. Paths Toward Democracy: Working Class and Elites in Western Europe and South America (Nueva York: Cambridge University Press).

Collier, Ruth Berins y David Collier. 1991. Shaping the Political Arena: Critical Junctures, the Labor Movement, and the Regime Dynamics in Latin America (Princeton: N.J. Princeton University Press).

Collier, Ruth Berins y Samuel Handlin (eds.). 2009. Reorganizing Popular Politics: Participation and the New Interest Regime in Latin America (University Park, Pa.: Pennsylvania State University Press).

Dahl, Robert A. 1971. Polyarchy (Nueva Haven, CT.: Yale University Press). [Versión en castellano: La poliarquía. Participación y oposición (Madrid: Editorial Tecnos, 1989).]

Diamond, Larry. 1999. Developing Democracy: Toward Consolidation (Baltimore, Md.: The Johns Hopkins University Press).

Diamond, Larry, Jonathan Hartlyn y Juan J. Linz. 1999. “Introduction: Politics, Society, and Democracy in Latin America", 1-70, en Larry Diamond, Jonathan Hartlyn, Juan J. Linz y Seymour Martin Lipset (eds.), Democracy in Developing Countries: Latin America (Boulder, Col.: Lynne Rienner Publishers, segunda edición).

Drake, Paul W. 1996. Labor Movements and Dictatorships: The Southern Cone in Comparative Perspective (Baltimore, Md.: The John Hopkins University Press). 
Drake, Paul. 2009. Between Tyranny and Anarchy: A History of Democracy in Latin America, 1800-2006 (Stanford, Cal.: Stanford University Press).

Drake, Paul y Lisa Hilbink. 2003. "Latin American Studies: Theory and Practice", en David L. Szanton (ed.), The Politics of Knowledge: Area Studies and the Disciplines. University of California Press/University of California International and Area Studies Digital Collection, Edited Volume \#3, 2003. http:// repositories.cdlib.org/uciaspubs/editedvolumes/3/2

Dunning, Thad. 2008. Crude Democracy: Natural Resource Wealth and Political Regimes (Nueva York: Cambridge University Press).

Eckstein, Harry. 1963. "A Perspective on Comparative Politics, Past and Present", 3-32, en Harry Eckstein y David Apter (eds.), Comparative Politics (Nueva York: Free Press).

Fails, Matthew D. y Heather Nicole Pierce. 2010. "Changing Mass Attitudes and Democratic Deepening", Political Research Quarterly 63 (1): 174-87.

Finer, Herman. 1932. The Theory and Practice of Modern Government 2 Volumes (Londres: Methuen). [Versión en castellano: Teoría y práctica del gobierno moderno (Madrid: Editorial Tecnos, 1964).]

Friedrich, Carl J. 1937. Constitutional Government and Politics: Nature and Development (Nueva York: Harper). [Versión revisada, en castellano: Gobierno Constitucional y Democracia. Teoría y Práctica en Europa y América, 2 Volúmenes (Madrid: IEP, 1975).]

Gandhi, Jennifer. 2008. Political Institutions under Dictatorship (Nueva York: Cambridge University Press).

Gandhi, Jennifer y Adam Przeworski. 2007. "Authoritarian Institutions and the Survival of Autocrats," Comparative Political Studies 40 (11): 1279-1301.

Geddes, Barbara. 2003. Paradigms and Sand Castles: Theory Building and Research Design in Comparative Politics (Michigan: University of Michigan Press).

Garretón, Manuel Antonio, Marcelo Cavarozzi, Peter S. Cleaves, Gary Gereffi y Jonathan Hartlyn. 2004. América Latina en el siglo XXI: Hacia una nueva matriz sociopolítica (Santiago de Chile: LOM Ediciones).

Germani, Gino. 1962. Política y sociedad en una época de transición (Buenos Aires: Paidós).

Greene, Kenneth F. 2007. Why Dominant Parties Lose: Mexico's Democratization in Comparative Perspective (Nueva York: Cambridge University Press).

Greene, Kenneth F. 2010. "The Political Economy of Authoritarian Single-Party Dominance”, Comparative Political Studies 43 (7): 807-34.

Hadenius, Axel y Jan Teorell. 2005. "Cultural and Economic Prerequisites of Democracy: Reassessing Recent Evidence", Studies in Comparative International Development 39 (4): 87-106.

Hartlyn, Jonathan y Arturo Valenzuela. 1994. "Democracy in Latin America since 1930", 99-162, 610-622, en Leslie Bethell (ed.), The Cambridge History of Latin America VI. Latin America since 1930 Part 2. Politics and Society (Nueva York: Cambridge University Press). [Versión en castellano: "La democracia en América Latina desde 1930", 9-66, 343-53, en Leslie Bethell (ed.), Historia de América Latina: 12. Política y sociedad desde 1930 (Barcelona: Crítica, 1997).]

Hirschman, Albert O. 1968. "The Political Economy of Import-Substituting Industrialization in Latin America", Quarterly Journal of Economics 82 (1): 1-32. [Versión en castellano: "La economía política de la industrialización a través de la sustitución de importaciones en América Latina", El Trimestre Económico 250 (1996): 489-524.]

Huber, Evelyne y Frank Safford (eds.). 1995. Agrarian Structure and Political Power. Landlord and Peasant in the Making of Latin America (Pittsburgh: University of Pittsburgh Press).

Huneeus, Carlos. 2006. "El lento y tardío desarrollo de la ciencia política en América Latina, 1966-2006", Estudios Internacionales 155: 137-56.

Huntington, Samuel P. 1997. "After Twenty Years: The Future of the Third Wave", Journal of Democracy 8 (4): 3-12.

Inglehart, Ronald. 1990. Culture Shift in Advanced Industrial Society (Princeton, N.J.: Princeton University Press). [Versión en castellano: El cambio cultural en la sociedad industrial avanzada (Madrid: Siglo XXI y Centro de Investigaciones Sociológicas, 1991).] 
Inglehart, Ronald y Christian Welzel. 2005. Modernization, Cultural Change, and Democracy (Nueva York: Cambridge University Press).

Inglehart, Ronald F. y Christian Welzel. 2007. “Modernization”, 3071-78, en George Ritzer (ed.), Blackwell Encyclopedia of Sociology (Nueva York: Blackwell).

Johnson, John J. 1958. Political Change in Latin America: The Emergence of the Middle Sectors (Stanford, Cal.: Stanford University Press).

Karl, Terry Lynn. 1990. "Dilemmas of Democratization in Latin America”, Comparative Politics 23 (1: 1-21. [Versión en castellano: "Dilemas de la democratización en América Latina", Foro Internacional 31 (3) (1991): 388-417.]

Karl, Terry Lynn. 1997. The Paradox of Plenty: Oil Booms and Petro-States (Berkeley, Cal.: University of California Press).

Landman, Todd. 1999. "Economic Development and Democracy: The View from Latin America", Political Studies 47 (1): 607-26.

Levitsky, Steven y Scott Mainwaring. 2006. "Organized Labor and Democracy in Latin America", Comparative Politics 39 (1): 21-42.

Lijphart, Arend. 1968. The Politics of Accommodation: Pluralism and Democracy in the Netherlands (Berkeley, Cal.: University of California Press).

Linz, Juan J. 1975. "Totalitarianism and Authoritarian Regimes", 175-411, en Fred Greenstein y Nelson Polsby (eds.), Handbook of Political Science 3, Macropolitical Theory (Reading, Mass.: Addison-Wesley Press). [Versión en castellano: “Regímenes totalitarios y autoritarios", Cap. 3 en Juan J. Linz, Obras escogidas 3. Sistemas totalitarios y regímenes autoritarios (Madrid: Centro de Estudios Políticos y Constitucionales, 2009).]

Linz, Juan J. 1978. The Breakdown of Democratic Regimes. Crisis, Breakdown, and Reequilibriation (Baltimore, Md.: The Johns Hopkins University Press). [Versión en castellano: La quiebra de las democracias (Madrid: Alianza, 1987).]

Linz, Juan J. 1994. "Presidential or Parliamentary Democracy: Does it Make a Difference?". 3-87, en Juan J. Linz y Arturo Valenzuela (eds.), The Failure of Presidential Democracy 1. Comparative Perspectives (Baltimore, Md.: The Johns Hopkins University Press). [Versión en castellano: “Democracia presidencial o parlamentaria. ¿Qué diferencia implica?". 25-146, en Juan J. Linz y Arturo Valenzuela (eds.), La crisis del presidencialismo 1. Perspectivas comparativas (Madrid: Alianza, 1997).]

Linz, Juan J. y Alfred Stepan. 1996. Problems of Democratic Transition and Consolidation: Southern Europe, South America and Post-Communist Europe (Baltimore, Md.: The Johns Hopkins University Press).

Linz, Juan J. y Arturo Valenzuela (eds.). 1994. The Failure of Presidential Democracy 2. The Case of Latin America (Baltimore, Md.: The Johns Hopkins University Press). [Versión en castellano: Juan J. Linz y Arturo Valenzuela (eds.), La crisis del presidencialismo 2. El caso de Latinoamérica (Madrid: Alianza, 1998).]

Lipset, Seymour Martin. 1959a. "Some Social Requisites of Democracy: Economic Development and Political Legitimacy", American Political Science Review 53 (1): 69-105. [Versión en castellano: "Algunos requisitos sociales de la democracia: Desarrollo económico y legitimidad política", 113-50, en Albert Batlle (ed.), Diez Textos Básicos de Ciencia Política (Madrid: Ariel, 1992).]

Lipset, Seymour Martin. 1959b. "Democracy and Working-Class Authoritarianism", American Sociological Review 24 (4): 482-501.

Lipset, Seymour Martin. 1994. "The Social Requisites of Democracy Revisited", American Sociological Review 59 (1): 1-22. [Versión en castellano: "Repensando los requisitos sociales de la democracia", La Política: Revista de estudios sobre el estado y la sociedad 2 (1996): 51-88.]

Lipset, Seymour Martin y Jason M. Lakin. 2004. The Democratic Century (Norman, OK.: University of Oklahoma Press).

Lipset, Seymour Martin y Stein Rokkan. 1967. “Cleavage Structures, Party Systems, and Voter Alignments: An Introduction", 1-64, en Seymour M. Lipset y Stein Rokkan (eds.), Party Systems and Voter Alignments: Cross-National Perspectives (Nueva York: Free Press). [Versión en castellano: "Estructuras de división, 
sistemas de partidos y alineamientos electorales", 231-73, en Albert Batlle (ed.), Diez Textos Básicos de Ciencia Política (Madrid: Ariel, 1992).]

López-Alves, Fernando. 2000. State Formation and Democracy in Latin America, 1810-1900 (Durham, N.C.: Duke University Press). [Versión en castellano: La formación del Estado y la democracia en América Latina, 1810-1900 (Bogotá, Norma, 2003).]

Magaloni, Beatriz. 2006. Voting for Autocracy: Hegemonic Party Survival and its Demise in Mexico (Nueva York: Cambridge University Press).

Mahoney, James. 2001. The Legacies of Liberalism: Path Dependence and Political Regimes in Central America (Baltimore, Md.: The Johns Hopkins University Press).

Mahoney, James y Richard Snyder. 1999. "Rethinking Agency and Structure in the Study of Regime Change", Studies in Comparative International Development 34 (2): 3-32.

Mainwaring, Scott. 1993. "Presidentialism, Multipartism, and Democracy: The Difficult Combination", Comparative Political Studies 26 (2: 198-228. [Versión en castellano: "Presidencialismo, multipartidismo y democracia: La difícil combinación", Revista de Estudios Políticos 88 (1995): 115-44.]

Mainwaring, Scott y Aníbal Pérez-Liñán. 2003. "Level of Development and Democracy: Latin American Exceptionalism, 1945-1996", Comparative Political Studies 36 (9): 1031-67. [Versión en castellano: “Nivel de desarrollo y democracia: el excepcionalismo latinoamericano (1945-1996)", América Latina Hoy 36: 189-224.]

Mainwaring, Scott y Aníbal Pérez-Liñán. 2005. “Latin American Democratization since 1978: Democratic Transitions, Breakdowns, and Erosions", 14-59, en Frances Hagopian y Scott P. Mainwaring (eds.), The Third Wave of Democratization in Latin America. Advances and Setbacks (Nueva York: Cambridge University Press).

Mazzuca, Sebastián L. 2007. "Reconceptualizing Democratization: Access to Power versus Exercise of Power", 39-49, en Gerardo L. Munck (ed.), Regimes and Democracy in Latin America. Theories and Methods (Oxford: Oxford University Press).

Mazzuca, Sebastián L. 2010. "Macro-foundations of Regime Change: State Formation and Capitalist Development", Comparative Politics 43 (1): 1-19.

Middlebrook, Kevin J. (ed.). 2000. Conservative Parties, the Right, and Democracy in Latin America (Baltimore, Md.: The Johns Hopkins University Press).

Moore, Jr., Barrington. 1966. Social Origins of Dictatorship and Democracy. Lord and Peasant in the Making of the Modern World (Boston: Beacon Press). [Versión en castellano: Orígenes sociales de la dictadura y la democracia: El señor y el campesino en la formación del mundo moderno (Barcelona: Ediciones Península, 1973).]

Morse, Richard M. 1964. "The Heritage of Latin America", 123-77, en Louis Hartz (ed.), The Founding of New Societies (Nueva York: Harcourt, Brace \& World, Inc.).

Mouzelis, Nicos P. 1986. Politics in the Semi-periphery: Early Parliamentarism and Late Industrialization in the Balkans and Latin America (Londrés: Macmillan).

Muller, Edward N. y Mitchell Seligson. 1994. "Civic Culture and Democracy: The Question of the Causal Relationships", American Political Science Review 88 (3): 635-52.

Munck, Gerardo L. 1998. Authoritarianism and Democratization. Soldiers and Workers in Argentina, 1976-83 (University Park, Pa.: Pennsylvania State University Press).

Munck, Gerardo L. 2002. "La transición a la política de masas en América Latina", Araucaria. Revista Iberoamericana de Filosofía, Política y Humanidades 3 (7): 95-132.

Munck, Gerardo L. 2007a. "Agendas y estrategias de investigación en el estudio de la política latinoamericana", Revista de Ciencia Política 27 (1): 3-21.

Munck, Gerardo L. 2007b. "The Study of Politics and Democracy: Touchstones of a Research Agenda", 25-37, en Gerardo L. Munck (ed.), Regimes and Democracy in Latin America. Theories and Methods (Oxford: Oxford University Press).

Munck, Gerardo L. 2009. "El pasado y presente de la política comparada en los Estados Unidos", Revista Latinoamericana de Política Comparada 2: 17-56. 
Munck, Gerardo L. 2010. "Repensando la cuestión democrática: La región Andina en el nuevo siglo", Revista de Ciencia Política 30 (1): 149-61.

Munck, Gerardo L. y Carol Leff. 1997. "Modes of Transition and Democratization. South America and Eastern Europe in Comparative Perspective", Comparative Politics 29 (3): 343-62.

Nun, José. 1967. "The Middle-Class Military Coup", 66-118, en Claudio Véliz (ed.), The Politics of Conformity in Latin America (Londrés: Oxford University Press).

O'Donnell, Guillermo. 1973. Modernization and Bureaucratic-Authoritarianism: Studies in South American Politics (Berkeley, Cal.: Institute of International Studies/University of California). [Versión en castellano: Modernización y autoritarismo (Buenos Aires: Editorial Paidós, 1972).]

O'Donnell, Guillermo. 1978. "State and Alliances in Argentina, 1956-1976", Journal of Development Studies 15 (1): 3-33. [Versión en castellano: “Estado y alianzas en la Argentina, 1956-76", Desarrollo Económico 64 (16) (1977): 523-54.]

O'Donnell, Guillermo. 1979. "Tensions in the Bureaucratic-Authoritarian State and the Question of Democracy", 285-318, en David Collier (ed.), The New Authoritarianism in Latin America (Princeton, N.J.: Princeton University Press). [Versión en castellano: "Las tensiones en el estado Burocrático Autoritario y la cuestión de la democracia", Cap. 2 en Guillermo Donnell, Catacumbas (Buenos Aires: Prometeo Libros, 2008).]

O'Donnell, Guillermo. 1982. 1966-1973. El Estado burocrático autoritario. Triunfos, derrotas y crisis (Buenos Aires: Editorial Belgrano).

O'Donnell, Guillermo. 2010. Democracy, Agency, and the State: Theory with Comparative Intent (Oxford: Oxford University Press).

O'Donnell, Guillermo y Philippe Schmitter. 1986. Transitions From Authoritarian Rule. Tentative Conclusions about Uncertain Democracies (Baltimore, Md.: The Johns Hopkins University Press). [Versión en castellano: Transiciones desde un gobierno autoritario 4. Conclusiones tentativas sobre las democracias inciertas (Buenos Aires: Paidós, 1994).]

O'Donnell, Guillermo, Osvaldo Iazzetta y Jorge Vargas Cullell (eds.). 2003. Democracia, desarrollo humano y ciudadanía (Rosario: Homo Sapiens).

Paige, Jeffery M. 1997. Coffee and Power: Revolution and the Rise of Democracy in Central America (Cambridge, Mass.: Harvard University Press).

Pérez-Stable, Marifeli. 1998. The Cuban Revolution: Origins, Course, and Legacy segunda edición (Oxford: Oxford University Press).

Przeworski, Adam. 1986. "Some Problems in the Study of the Transition to Democracy", 47-63, en Guillermo O'Donnell, Philippe Schmitter y Laurence Whitehead (eds.), Transitions from Authoritarian Rule. Comparative Perspectives (Baltimore, Md.: The Johns Hopkins University Press). [Versión en castellano: "Algunos problemas en el estudio de la transición hacia la democracia", 79-104, en Guillermo O'Donnell, Philippe Schmitter y Lawrence Whitehead (eds.), Transiciones desde un gobierno autoritario 3. Perspectivas comparadas (Buenos Aires: Paidós, 1994).]

Przeworski, Adam. 1991. Democracy and the Market. Political and Economic Reforms in Eastern Europe and Latin America (Nueva York: Cambridge University Press). [Versión en castellano: Democracia y mercado: Reformas políticas y económicas en la Europa del Este y América Latina (Cambridge, Cambridge University Press, 1995).]

Przeworski, Adam. 2006. "Self-enforcing Democracy", 312-28, en Barry R. Weingast y Donald Wittman (eds.), Oxford Handbook of Political Economy (Nueva York: Oxford University Press).

Przeworski, Adam. 2009. "The Mechanics of Regime Instability in Latin America", Journal of Politics in Latin America 1: 5-36.

Przeworski, Adam, Michael E. Alvarez, José Antonio Cheibub y Fernando Limongi. 2000. Democracy and Development: Political Institutions and Well-Being in the World, 1950-1990 (Nueva York: Cambridge University Press).

Przeworski, Adam, José Antônio Cheibub y Fernando Limongi. 2004. "Democracia y Cultura Política", Metapolítica 33 (8): 52-69. 
Przeworski, Adam y Fernando Limongi. 1997. "Modernization: Theories and Facts", World Politics 49 (2): 155-83.

Rouquié, Alain. 1984. El Estado Militar en America Latina (México: Siglo XXI).

Rueschemeyer, Dietrich, John D. Stephens y Evelyne Huber Stephens. 1992. Capitalist Development and Democracy (Chicago: University of Chicago Press).

Schmitter, Philippe C. 2009. “Twenty-five Years, Fifteen Findings”, Journal of Democracy 21 (1): 17-28.

Schmitter, Philippe y Terry Karl. 1991. "What Democracy is...and What it is Not", Journal of Democracy 2 (3) (Summer): 75-88.

Schneider, Carsten Q. 2009. The Consolidation of Democracy: Comparing Europe and Latin America (Londrés: Routledge).

Scully, Timothy R. 1992. Rethinking the Center. Party Politics in Nineteenth-and Twentieth-Century Chile (Stanford, Cal.: Stanford University Press). [Versión en castellano: Los partidos de centro y la evolución política chilena (Santiago: Editorial CIEPLAN, 1992).]

Smith, Peter H. 2005. Democracy in Latin America: Political Change in Comparative Perspective (Nueva York: Oxford University Press).

Snyder, Richard. 1998. "Paths out of Sultanistic Regimes: Combining Structural and Voluntarist Perspectives", 49-81, 244-55, en H.E. Chehabi y Juan J. Linz (eds.), Sultanistic Regimes (Baltimore, Md.: The Johns Hopkins University Press).

Stradiotto, Gary A. 2009. "The Democratic Revolution", tesis de doctorado, Departamento de Ciencias Políticas, Universidad de California, Davis.

Tanaka, Martin (ed.). 2009. La nueva conyuntura crítica en los países andinos (Lima: IEP e IDEA Internacional).

Teorell, Jan y Axel Hadenius. 2006. “Democracy without Democratic Values: A Rejoinder to Welzel and Inglehart", Studies in Comparative International Development 41 (3): 96-111.

Therborn, Göran. 1977. "The Rule of Capital and the Rise of Democracy", New Left Review 103: 3-41.

Therborn, Göran. 1979. "The Travails of Latin American Democracy", New Left Review 113/114: 71-109.

Touraine, Alain. 1987. Actores sociales y sistemas politicos en América Latina (Santiago de Chile: PREALC/ OIT).

Touraine, Alain. 1989. América Latina: Política y sociedad (Madrid: Espasa-Calpe).

Valenzuela, Arturo. 1978. The Breakdown of Democratic Regimes: Chile (Baltimore, Md.: The Johns Hopkins University Press). [Versión en castellano: El quiebre de la democracia en Chile (Santiago de Chile: FLACSO, 1989).]

Valenzuela, Arturo. 1988. "Political Science and the Study of Latin America", 63-86, en Christopher Mitchell (ed.), Changing Perspectives in Latin American Studies (Stanford, Cal.: Stanford University Press).

Valenzuela, Arturo y Samuel Valenzuela. 1983. “Los orígenes de la democracia: Reflexiones teóricas sobre el caso de Chile", Estudios Públicos 12: 3-39.

Valenzuela, J. Samuel. 2001. “Class Relations and Democratization: A Reassessment of Barrington Moore's Model", 240-86, en Miguel Angel Centeno y Fernando López-Alves (eds.), The Other Mirror: Grand Theory Through the Lens of Latin America (Princeton, N.J.: Princeton University Press).

Valenzuela, J. Samuel y Arturo Valenzuela. 1978. "Modernization and Dependency: Alternative Perspectives in the Study of Latin American Development", Comparative Politics 10 (4): 535-52. [Versión en castellano: "Modernización y dependencia: perspectivas alternas en el estudio del subdesarrollo latinoamericano", 43-76, en José J. Villamil (ed.), Capitalismo transnacional y desarrollo nacional (México: Fondo de Cultura Económica, 1979).]

Véliz, Claudio. 1980. The Centralist Tradition of Latin America (Princeton, N.J.: Princeton University Press). [Versión en castellano: La tradición centralista de America Latina (Barcelona: Ariel, 1984).]

Waisman, Carlos H. 1987. Reversal of Development in Argentina. Postwar Counterrevolutionary Policies and Their Structural Consequences (Princeton, N.J.: Princeton University Press). 
Wiarda, Howard J. 2001. The Soul of Latin America: The Cultural and Political Tradition (Nueva Haven, CT.: Yale University Press).

Yashar, Deborah. 1997. Demanding Democracy: Reform and Reaction in Costa Rica and Guatemala, 1870s-1950s (Stanford, Cal.: Stanford University Press).

Gerardo L. Munck, argentino de nacimiento, es profesor en el Colegio de Relaciones Internacionales de la Universidad del Sur de California (USC), y se dedica a la investigación sobre regímenes políticos y democracia, metodología, y América Latina. Sus publicaciones incluyen Measuring Democracy: A Bridge Between Scholarship and Politics (Johns Hopkins, 2009); Regimes and Democracy in Latin America (Oxford, 2007); Passion, Craft, and Method in Comparative Politics (con Richard Snyder; Johns Hopkins, 2007); y Authoritarianism and Democratization. Soldiers and Workers in Argentina, 1976-83 (Penn State, 1998). Fue parte del equipo que trabajó en el informe del Programa de Naciones Unidas para el Desarrollo (PNUD), La democracia en América Latina. Hacia una democracia de ciudadanas y ciudadanos (2004), y en el informe de la Organización de Estados Americanos (OEA) y el PNUD, Nuestra Democracia (2010).

(E-mail: munck@usc.edu). 
